\title{
Corrosion resistance of AISI 304 and 444 stainless steel pipes in sanitizing solutions of clean-in-place process
}

\author{
Vanessa de Freitas Cunha Lins ${ }^{a *}$, Giselle Aline dos Santos Gonçalves ${ }^{b}$, Tiago Paschoalin Leão ${ }^{c}$ \\ Renata Braga Soares ${ }^{a}$, Cíntia Gonçalves Fonseca Costa ${ }^{a}$, Adolfo Kalergis do Nascimento Viana ${ }^{d}$ \\ ${ }^{a}$ Chemical Engineering Department, Federal University of Minas Gerais - UFMG, \\ Avenida Antonio Carlos, 6627, CEP 32270-901, Belo Horizonte, MG, Brazil \\ ${ }^{b}$ AMBEV, Professor Jose Vieira Mendonça, 1435, CEP 31310-260, Belo Horizonte, MG, Brazil \\ ${ }^{c}$ Metallurgical and Materials Department, Federal University of Minas Gerais - UFMG, \\ Avenida Antonio Carlos, 6627, CEP 32270-901, Belo Horizonte, MG, Brazil \\ ${ }^{d}$ APERAM South America, Praça $1^{\circ}$ de Maio, CEP 35180-018, Timóteo, MG, Brazil
}

Received: May 22, 2015; Revised: October 17, 2015; Accepted: December 21, 2015

\begin{abstract}
Stainless steel (SS) is successfully used in food industries due to the characteristics of its surface, which is essential for the maintenance of the properties of food. Tanks and stainless steel pipes, which come into direct contact with food and drink, undergo a process of cleaning and disinfecting called CIP (Clean-in-Place). This method consists of automatic recirculation of a detergent solution for a controlled time followed by a rinsing with water, and finally a cleaning and sanitizing solution immersion. This work consists of investigating the corrosion resistance of stainless steels used in the food industry using sanitizing solutions employed in the CIP procedure, and using electrochemical techniques such as potentiodynamic anodic polarization and electrochemical impedance spectroscopy.
\end{abstract}

Keywords: Stainless steel, Sanitizing, Electrochemical impedance spectroscopy, Corrosion, Potentiodynamic anodic polarization

\section{1- Introduction}

Microbiological contamination can affect the quality, operation and safety of products produced in the food industry and can cause microbiological induced corrosion (MIC) of equipment and packaging. The Clean-In-Place (CIP) process, which is applied to avoid microbiological contamination, involves blasting or spraying on surfaces or the circulation of cleaning products in the stainless steel pipelines at a given flow. The CIP process usually involves a sequence of application of caustic soda (sodium hydroxide) and nitric acid for cleaning, chemicals capable of removing organic compounds such as proteins, fats and inorganics (calcium, phosphate and other chemicals). A sanitizing agent is also applied. Traditionally sodium hypochlorite is used as a sanitizing agent; however, a wide variety of quaternary ammonium compounds such as acids and chlorine-based compounds can be used as sanitizers in the CIP process ${ }^{1}$.

Stainless steel (SS) is successfully used in food industries due to the characteristics of its surface, which is essential for the maintenance of properties, preservation and conservation of food ${ }^{1}$.

However, it is known that pitting corrosion can occur in stainless steel, and the localized corrosion resistance of steel depends on the concentration of chloride in the environment 2. Electrochemical methods, particularly electrochemical impedance spectroscopy (EIS), have been suggested as an efficient tool to study the corrosion behavior of metals,

*e-mail: vlins@deq.ufmg.br which provide information about the corrosion resistance and reaction mechanisms ${ }^{2-4}$.

Research studies ${ }^{2,5-10}$ have been performed on corrosion resistance of AISI 304 steel in several media, but no research is reported on the corrosion behavior of the AISI 304 and 444 steels exposed to cleansing and sanitizing solutions used in CIP process.

This work is aimed at evaluating corrosion resistance of AISI 304 and 444 stainless steels treated with cleansing and sanitizing solutions of the CIP process, employing electrochemical techniques.

\section{2- Materials and Methods}

The sanitizing electrolytes used in the CIP process were: calcium hypochlorite (3 ppm), and Divosan (aqueous solution of $0.25 \% \mathrm{v} / \mathrm{v}$ peracetic acid, $0.25 \% \mathrm{v} / \mathrm{v}$ acetic acid, $0.25 \%$ $\mathrm{v} / \mathrm{v}$ hydrogen peroxide). The $\mathrm{pH}$ and conductivity of each electrolyte were measured using Metrohm $780 \mathrm{pH}$ meter and Metrohm 856 conductivity module equipment.

The stainless steels studied are AISI 304 and 444 steels, whose chemical composition is shown in Table 1. The pitting resistance number (PREN) of the AISI 304 steel is 19.1 and the PREN of the $444 \mathrm{SS}$ is $23.9^{11}$. The steel samples were provided by Aperam South America industry.

The stainless steels were cold rolled, annealed at $1060^{\circ} \mathrm{C}$ (AISI 304 steel) and at $1080^{\circ} \mathrm{C}$ (AISI 444 steel) and submitted to the skin pass. 
Table 1. Chemical composition of stainless steels (\%-wt)

\begin{tabular}{|c|c|c|c|c|c|c|c|c|c|}
\hline Steel & C & Mn & Si & $\mathbf{P}$ & $\mathbf{S}$ & $\mathrm{Cr}$ & $\mathbf{N i}$ & Мo & Al \\
\hline 304 & 0.043 & 1.16 & 0.41 & 0.032 & 0.0018 & 18.15 & 8.03 & 0.073 & 0.003 \\
\hline 444 & 0.011 & 0.14 & 0.48 & 0.027 & 0.0006 & 17.64 & 0.19 & 1.826 & 0.006 \\
\hline Steel & Co & $\mathbf{V}$ & $\mathrm{Nb}$ & Ti & B & $\mathbf{N}(\mathbf{p p m})$ & $O(p p m)$ & $\mathrm{Cu}$ & Sn \\
\hline 304 & 0.130 & 0.041 & 0.014 & 0.003 & 0.0005 & 471 & 35 & 0.10 & 0.005 \\
\hline 444 & 0.021 & 0.041 & 0.184 & 0.143 & - & 122 & 32 & 0.02 & 0.001 \\
\hline
\end{tabular}

The average grain size of the AISI 304 steel with a thickness of $0.5 \mathrm{~mm}$ was ASTM 8. The AISI 304 steel showed a hardness of $78 \mathrm{HRB}$, yield strength of $283 \mathrm{MPa}$, elongation of $56 \%$, and an ultimate tensile strength of $681 \mathrm{MPa}$.

The average grain size of the AISI 444 steel with a thickness of $1 \mathrm{~mm}$ was ASTM 7. The AISI 444 steel showed a hardness of $80 \mathrm{HRB}$, yield strength of $342 \mathrm{MPa}$, elongation of $32 \%$, and an ultimate tensile strength of $498 \mathrm{MPa}$.

The electrochemical impedance spectroscopy (EIS) was performed in a $300 \mathrm{~mL}$ electrochemical cell by varying the frequency from $1 \mathrm{MHz}$ to $1 \mathrm{mHz}$ using a potential amplitude of $10 \mathrm{mV}$. Previous research was performed varying the potential amplitude from $5 \mathrm{mV}$ to $20 \mathrm{mV}$, and, by using the potential amplitude of $10 \mathrm{mV}$, the results were optimized. The open circuit potential was measured for a minimum time period of one hour before each EIS measurement or until stabilization.

The cyclic potentiodynamic polarization (CPP) test was performed starting from a potential below the corrosion potential $(20 \mathrm{mV})$ of each sample up to $1.3 \mathrm{~V}$, which is the scan reversal potential. The scan rate used was $0.167 \mathrm{mV} / \mathrm{s}$.

All measurements were performed using a PRINCETON Applied Research Versastat3 potentiostat; the reference electrode used was $\mathrm{Ag} / \mathrm{AgCl}, \mathrm{KCl}$ (sat), and the counter electrode was platinum. The working electrode was a steel sample with $1 \mathrm{~cm}^{2}$ of area. The samples were degreased with an alcohol solution, washed with distilled water and dried with blown air. The collection, storage, and processing of data were performed using the Versa Studio software. Data processing was accomplished by running the program ZView. The electrochemical tests were performed with a minimum of five replicates.

\section{3- Results}

The results of $\mathrm{pH}$ and conductivity of the electrolytes used are shown in Table 2.

Sanitizing Divosan is an acid sanitizing and calcium hypochlorite is a neutral sanitizing with a higher conductivity than the Divosan solution.

The Bode diagrams of impedance modulus and of phase angle versus frequency of AISI 304 and AISI 444 SS in calcium hypochlorite and Divosan are shown in Figure 1 and Figure 2, respectively. Bode diagrams of impedance modulus showed one inflection point and Bode diagrams of phase angle versus frequency showed one maximum indicating the one time constant of the processes for all samples. Phase angles associated with maxima were similar for both media, and the difference between the resistive behaviors of the steel in the two electrolytes was not identified.
Figure 3 shows a Nyquist diagram of AISI 304 and AISI 444 steel in media of Divosan (a) and calcium hypochlorite solution (b). The EIS results were interpreted in terms of equivalent electrical circuits shown in Figure 3, where Rs is the electrolyte resistance, $\mathrm{Rp}$ is the polarization resistance, and $\mathrm{CPE}$ is the constant phase element. The polarization resistance $(\mathrm{Rp})$ is associated with the corrosive process between the metal and the solution, which occurs through the protective passive film. The Nyquist plots of the studied samples exhibited only one time constant and the semi-circles were flattened and centered below the real impedance axis. This behavior is typical of solid metal electrodes that show a frequency dispersion of the capacitive properties and can be modeled using a constant phase element (CPE) ${ }^{12-14}$. The impedance of a CPE, $Z_{\mathrm{CPE}}$, is defined in Equation $1^{12-14}$ :

$$
Z_{C P E}=\frac{1}{Q(j \omega)^{n}}
$$

in which $Q$ is the CPE magnitude $\left(\Omega^{-1} \mathrm{~cm}^{-2} \mathrm{~s}^{\mathrm{n}}\right), \mathrm{j}^{2}=-1, \mathrm{n}$ is the CPE exponent, and $\omega$ is the angular frequency. The magnitude of $n$ is $0 \leq n \leq 1$ but $n$ is often close to 1 and the CPE behaves as a capacitor when $n=1$.

The results of cyclic potentiodynamic polarization tests of AISI 304 and AISI 444 SS in media of Divosan (a) and calcium hypochlorite (b) are shown in Figure 4.

Table 3 shows the electrochemical parameters obtained using cyclic potentiodynamic polarization tests and electrochemical impedance spectroscopy. The polarization resistance values were obtained by fitting the EIS data to the equivalent circuit $\mathrm{R}_{\mathrm{s}}\left(\mathrm{QR}_{\mathrm{p}}\right)$, shown in Figure 3 .

On the surface of AISI 304 SS in Divosan and calcium hypochlorite electrolytes, some pits were observed, associated to the polishing scratches (Figures 5 and 6). On the surface of AISI 444 steel, a more superficial corrosion along specific directions (polishing directions) and rare pits were observed (Figures 7 and 8).

\section{4- Discussion}

The Kramers-Kroning (K-K) relationships were applied to check the validity of experimental results. Any system that satisfies the a priori conditions of linearity, stability, and causality must satisfy the K-K relationships. The K-K technique transforms the real component into the imaginary component and vice versa, so that the transformed quantities may be compared directly with their corresponding experimental values for the same parameters. An agreement between the experimental and transformed impedance data for both real and imaginary components validates the EIS data ${ }^{15}$. 
Table 2. Values of $\mathrm{pH}$ and conductivity of electrolytes

\begin{tabular}{lllc}
\hline \multicolumn{1}{c}{ Electrolyte } & \multicolumn{1}{c}{ Concentration $(\% \mathrm{v} / \mathrm{v})$} & $\mathbf{p H}$ & Conductivity $(\mathrm{mS})$ \\
\hline Divosan & $\begin{array}{l}0.25 \% \mathrm{v} / \mathrm{v} \text { peracetic acid, } 0.25 \% \mathrm{v} / \mathrm{v} \text { acetic acid, } 0.25 \% \mathrm{v} / \mathrm{v} \\
\text { hydrogen peroxide }\end{array}$ & 3.1 & 0.02 \\
Calcium hypochlorite & $3 \mu \mathrm{g} / \mathrm{g}$ solution & 7.4 & 0.12 \\
\hline
\end{tabular}

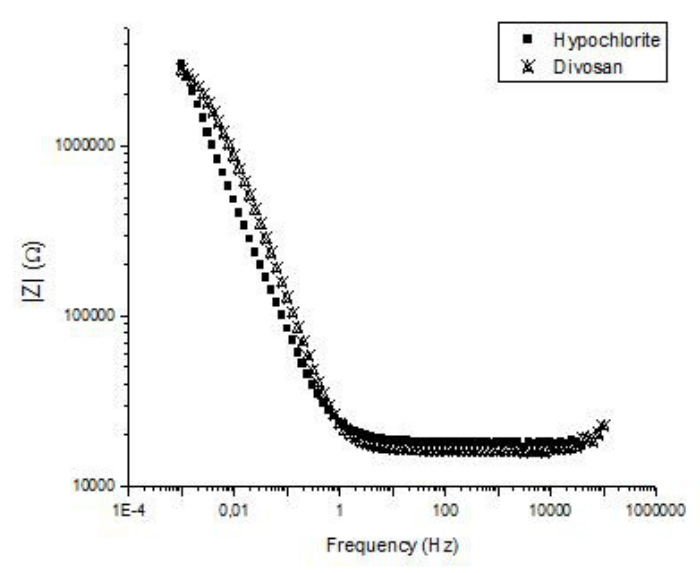

(a)

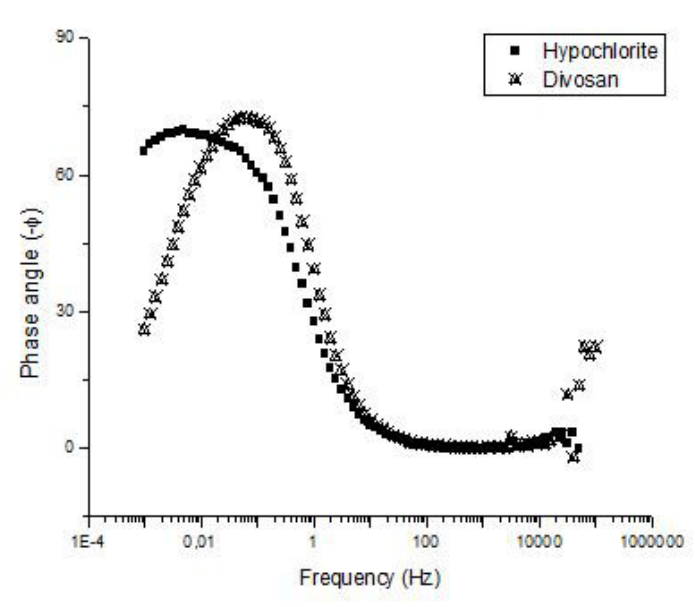

(b)

Figure 1. Bode diagram of impedance modulus (a) and phase angle (b) of AISI 304 SS in calcium hypochlorite solution and Divosan.

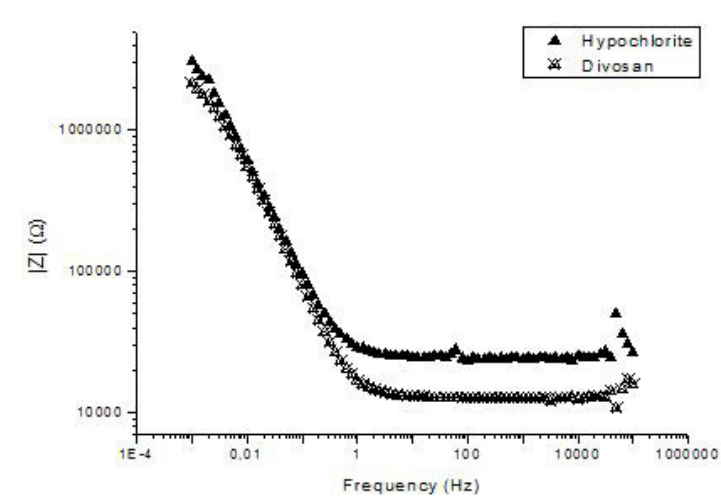

(a)

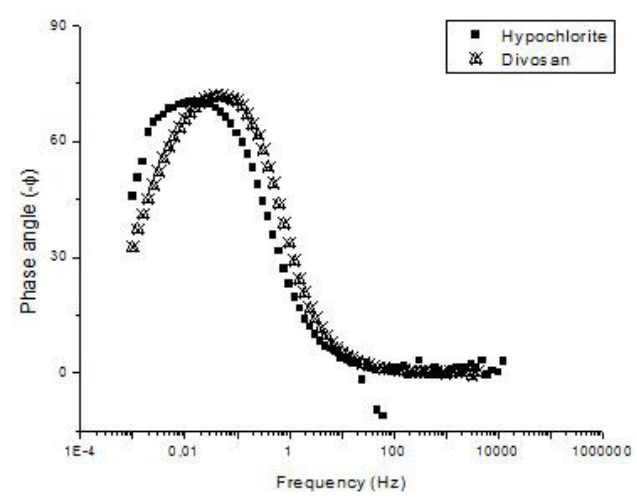

(b)

Figure 2. Bode diagrams of impedance modulus (a) and phase angle (b) of AISI 444 SS in calcium hypochlorite solution and Divosan.

Considering the availability for the use of the two sanitizers, and the corrosion resistance of the steel in the two electrolytes, the aqueous solution of calcium hypochlorite was less aggressive to the studied stainless steels. Both steels showed a higher polarization resistance value, and higher or similar transpassive potential values in a calcium hypochlorite aqueous solution than in the Divosan electrolyte. The AISI 304 steel showed a similar transpassive potential for the two electrolytes, but a lower value of passivation current density in the calcium hypochlorite solution than in the
Divosan solution. Figure 4 shows a negative hysteresis in the CPP curves for all samples. Often, a negative hysteresis is observed where the passive current on the reverse scan is lower than that on the forward scan. Pitting and crevice corrosion are usually not found in association with such a CPP curve or the pits have no tendency to propagate, as in this case.

Although the calcium hypochlorite solution showed a higher conductivity than the Divosan medium, the calcium hypochlorite solution is neutral and is a strong oxidizer that 


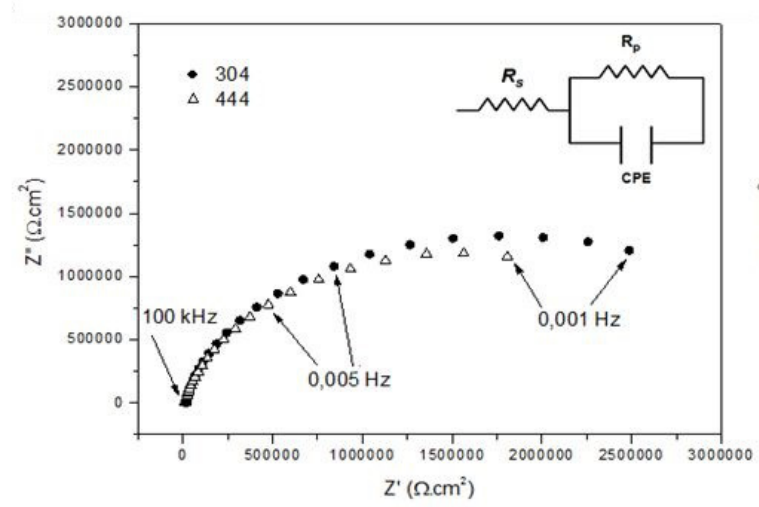

(a)

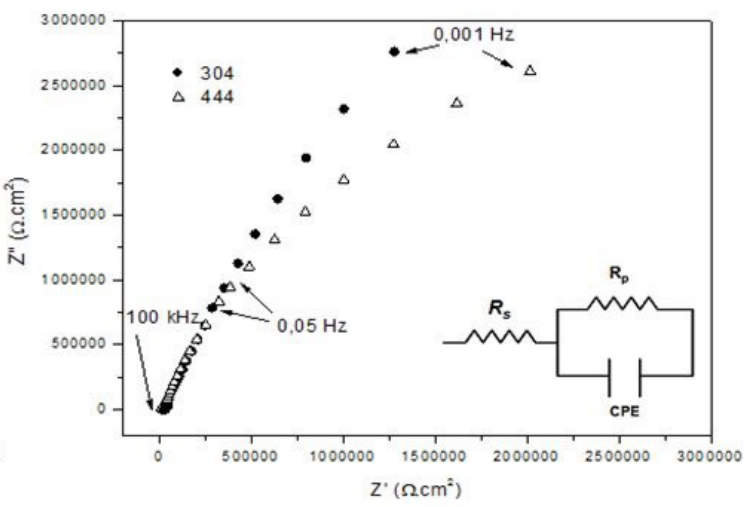

(b)

Figure 3. Nyquist diagrams of AISI 304 and AISI 444 SS in medium of Divosan (a) and calcium hypochlorite (b).

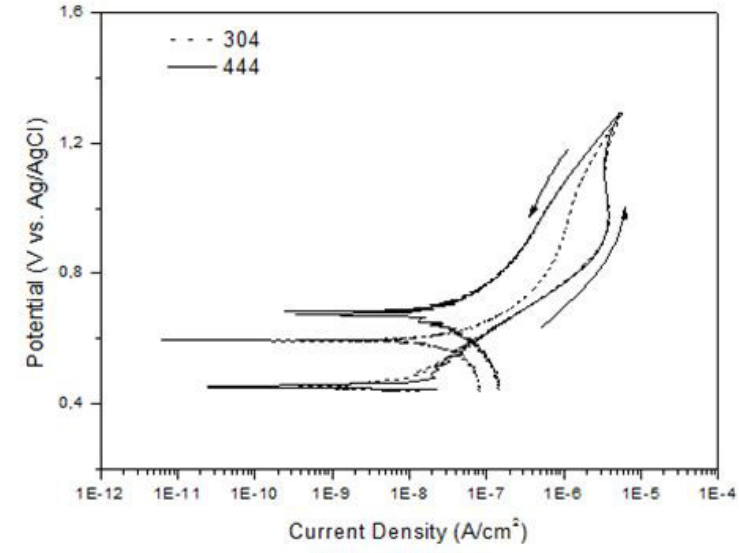

(a)

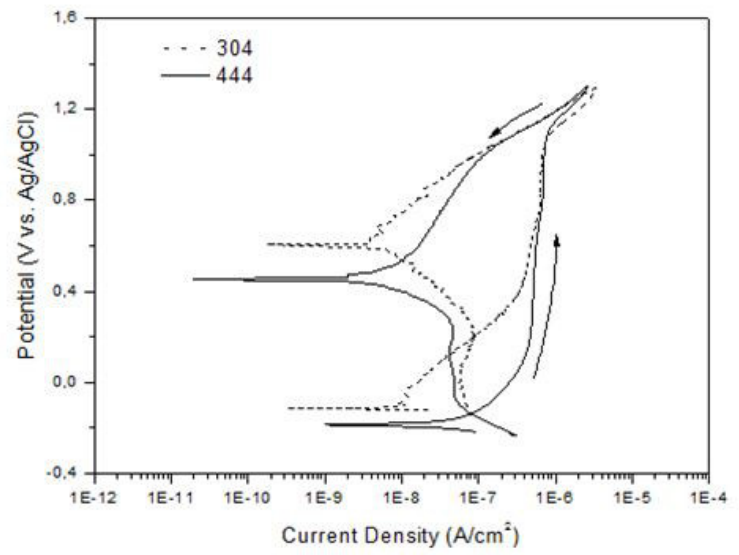

(b)

Figure 4. Cyclic potentiodynamic polarization tests of AISI 304 and AISI 444 SS in media of Divosan (a) and calcium hypochlorite (b).

Table 3. Electrochemical parameters obtained using polarization and electrochemical impedance spectroscopy

\begin{tabular}{|c|c|c|c|c|c|c|}
\hline Electrolyte & $\begin{array}{c}\text { Rp } \\
\left(\mathrm{M} \Omega . \mathrm{cm}^{2}\right) \\
\text { AISI } 304\end{array}$ & $\begin{array}{c}\text { Rp } \\
\left(\mathrm{M} \Omega . \mathbf{c m}^{2}\right) \\
\text { AISI } 444\end{array}$ & $\begin{array}{c}\text { Etransp. } \\
\text { V(SCE) } \\
\text { AISI } 304\end{array}$ & $\begin{array}{c}\text { Etransp. } \\
\text { V(SCE) } \\
\text { AISI } 444\end{array}$ & $\begin{array}{c}\text { Ipass. } \\
\text { A/cm² } \\
\text { AISI } 304\end{array}$ & $\begin{array}{c}\text { Ipass. } \\
\text { A/cm² } \\
\text { AISI } 444\end{array}$ \\
\hline Divosan & $3.05 \pm 0,17$ & $2.72 \pm 0.09$ & 1.10 & 0.80 & $1.10^{-6}$ & $5.10^{-7}$ \\
\hline Calcium hypochlorite & $26.05 \pm 4.82$ & $6.80 \pm 0.67$ & 1.07 & 1.09 & $7.10^{-7}$ & $7.10^{-7}$ \\
\hline
\end{tabular}

can contribute to the passivation process of the SS steels. The calcium hypochlorite, $\mathrm{Ca}(\mathrm{OCl})_{2}$, reacts with water according to Equation 2:

$\mathrm{Ca}(\mathrm{OCl})_{2}+2 \mathrm{H}_{2} \mathrm{O} \leftrightarrow 2 \mathrm{HOCl}+\mathrm{Ca}(\mathrm{OH})_{2}$

The cathodic reaction in a neutral medium is shown in Equation $3^{16}$ :

$2 \mathrm{H}_{2} \mathrm{O}+\mathrm{O}_{2}+4 \mathrm{e}^{-} \leftrightarrow 4 \mathrm{OH}^{-}$

This reaction requires the presence of oxygen in solution and the diffusion of oxygen to the cathodic area.
In an acid medium of Divosan, a cathodic reaction of hydrogen reduction can occur without the need to supply oxygen ${ }^{16}$. In a Divosan solution, an extra supply of oxygen can occur by hydrogen peroxide decomposition. Oxygen can react with water and hydrogen ions consuming electrons, accelerating the corrosion of metal. This fact contributes to the higher corrosiveness of the Divosan medium.

Peracetic acid has a reasonably strong acidity due to the presence of three oxygen ions in the carboxyl group $(\mathrm{pKa}=8.2)$, and is extremely aggressive and corrosive to iron ${ }^{17}$. Some possible reactions of peracetic acid are: decomposition in acetic acid with oxygen delivery, which 


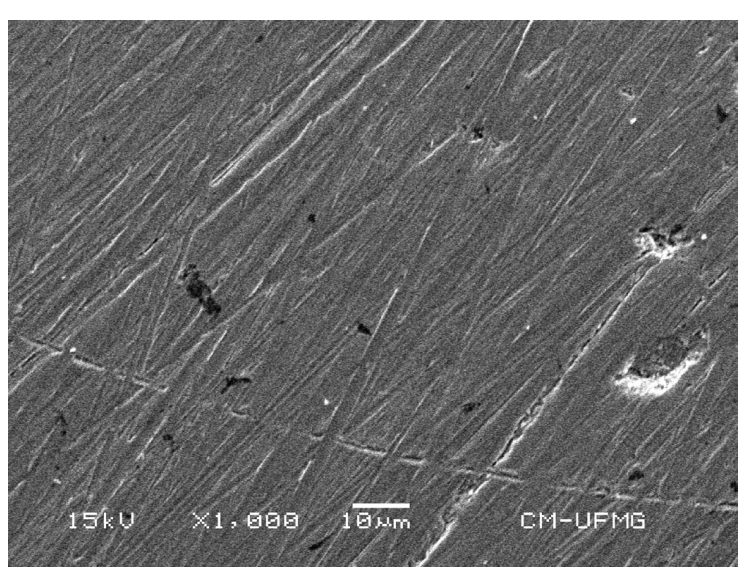

Figure 5. Surface of the AISI 304 steel after cyclic potentiodynamic polarization test in medium of Divosan

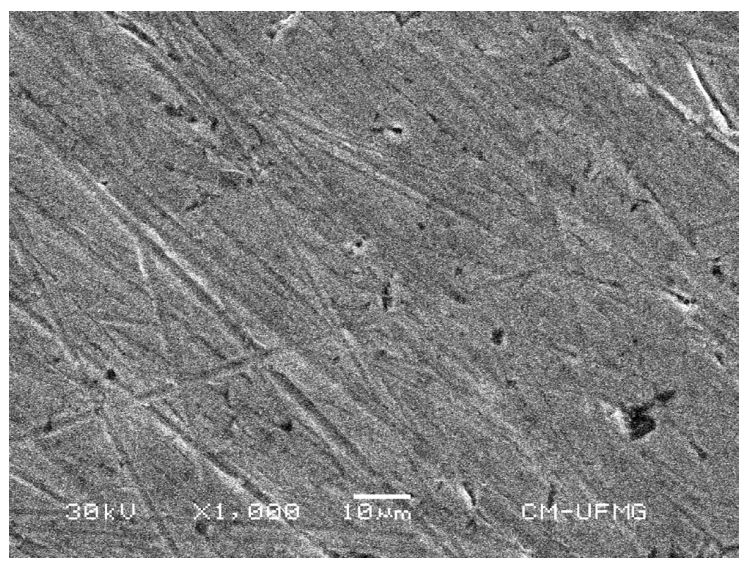

Figure 6. Surface of the AISI 304 steel after cyclic potentiodynamic polarization test in medium of calcium hypochlorite solution

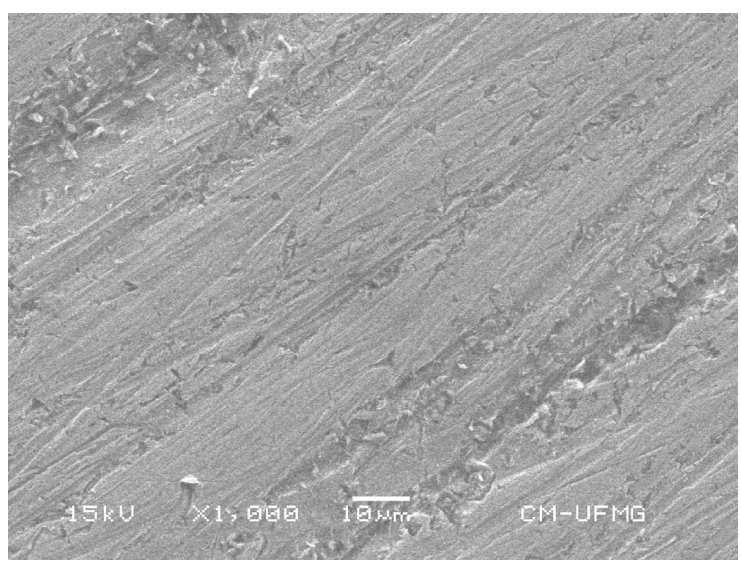

Figure 7. Surface of the AISI 444 steel after cyclic potentiodynamic polarization test in medium of Divosan

is thermodynamically favorable, dissociation in an aqueous medium with formation of peracetate ions and hydrogen ions, and peracetic acid formation by reaction of hydrogen peroxide and acetic acid ${ }^{17}$.

The peracetic acid generation is reversible and is impractically slow in the absence of an acid catalyst, but

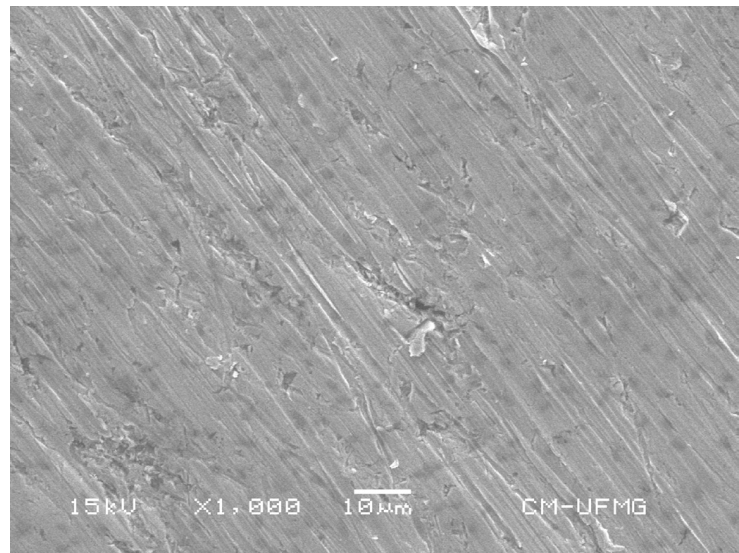

Figure 8. Surface of the AISI 444 steel after cyclic potentiodynamic polarization test in medium of calcium hypochlorite solution

may be favored by the decomposition of peracetic acid in acetic acid (Le Chatelier's Principle). Another possibility is also the decomposition of hydrogen peroxide into water and oxygen gas. There must be, furthermore, the dissociation of acetic acid in acetate ions and hydrogen ions, due to the $\mathrm{pKa}$ value $=4.75$ of acetic acid ${ }^{17}$. The generation of oxygen and hydrogen ions which are reagents in cathodic reactions (reduction of hydrogen and oxygen) contributed to accelerate the corrosion of stainless steel in the medium of the Divosan solution.

Expected species in solution are peracetate ion $\left(\mathrm{CH}_{3} \mathrm{COOO}\right)$, acetate ions $\left(\mathrm{CH}_{3} \mathrm{COO}^{-}\right)$, and hydrogen $\left(\mathrm{H}^{+}\right)$ions, in addition to the molecular species $\mathrm{CH}_{3} \mathrm{COOH}, \mathrm{CH}_{3} \mathrm{COOOH}$ and $\mathrm{H}_{2} \mathrm{O}_{2}{ }^{17}$.

Comparing the two stainless steels in both media, the AISI 444 showed lower values of polarization resistance in the two electrolytes and a lower value of breakdown potential in the Divosan medium. In the calcium hypochlorite solution, according to the polarization curves, the two steels showed a high corrosion resistance and no significant difference in corrosion behavior was identified. But in the Divosan electrolyte, the AISI 444 steel showed a lower value of the transpassive potential.

Considering the polarization results, a negative hysteresis was obtained for both steels, indicating a low severity of localized corrosion attack. In this case, the propagation of pits is inhibited. A higher concentration of pits was observed on the surface of the 304 SS than on the surface of 444 SS, which can be associated to the highest pitting resistance number (PREN) ${ }^{11}$ of the 444 SS.

The highest corrosion resistance of AISI 304 steel in both electrolytes, according to the and polarization results, may be due to the higher contents of nitrogen and nickel than in the AISI 444 steel. Willenbruch et al. ${ }^{18}$ reported that nitride acts as a precursor to the formation of the oxide passive film, with the following interfacial reaction (Equation 4) taking place:

$2 \mathrm{CrN}+3 \mathrm{H}_{2} \mathrm{O}_{\text {ads }} \leftrightarrow \mathrm{Cr}_{2} \mathrm{O}_{3}+2 \mathrm{NH}_{3}$

Willenbruch et al., ${ }^{18}$ showed evidence for the effectiveness of the alloy nitride phase as a kinetic barrier in the case of the AISI 304 steel in which after the oxidation of 40 monolayers of steel, a surface nitride is still observed. This nitride 
layer separates the metal phase from the electrolyte, in the active range, and the passive film and the metal in the passive range of potentials. Furthermore, the nitride phase may be responsible for aiding repassivation of pit nucleii by (a) preventing active dissolution (b) decreasing local acidity by formation of ammonium ions and (c) providing a rich supply of $\mathrm{Cr}$ and $\mathrm{Mo}$ for oxide film formation ${ }^{8}$. Thus, nitrogen plays an important role in the corrosion resistance of 304 SS. Corroborant the highest corrosion resistance of the $304 \mathrm{SS}$, McCafferty ${ }^{19}$ reports that the critical current density for passivation was higher for the ferritic 430 steel than for the austenitic AISI 304 steel. Molybdenum ${ }^{10,20}$ is also a beneficial element for passivation. McCafferty ${ }^{19}$ reports that $\mathrm{MoO}_{4}^{2-}$ is the basis for a cation-selective outer layer of the passive film hindering the inward passage of aggressive anions and preventing the degradation of the passive layer.

However, in this work, nitrogen and nickel play the predominant role in relation to the corrosion resistance.

\section{References}

1. Bremer PJ, Fillery S and McQuillan J. Laboratory scale Clean-InPlace (CIP) studies on the effectiveness of different caustic and acid wash steps on the removal of dairy biofilms. International Journal of Food Microbiology. 2006; 106(3):254-262. http:// dx.doi.org/10.1016/j.ijfoodmicro.2005.07.004.

2. Hong $\mathrm{T}$ and Nagumo $\mathrm{M}$. The effect of chloride concentration on early stages of pitting for 304 stainless steel revealed by the AC impedance method. Corrosion Science. 1997; 39(2):285-293, 1997. http://dx.doi.org/10.1016/S0010-938X(96)00127-8.

3. Della Rovere CA, Alano JH, Otubo J and Kuri SE. Corrosion behavior of shape memory stainless steel in acid media. Journal of Alloys and Compounds. 2011; 509(17):5376-5380. http:// dx.doi.org/10.1016/j.jallcom.2011.02.051.

4. Farias CA and Lins VF. Corrosion resistance of steels used in alcohol and sugar industry. Chemical Engineering \& Technology. 2011;34(9):1393-1401. http://dx.doi.org/10.1002/ ceat.201000542.

5. García C, Martín F, De Tiedra P, Heredero JA and Aparicio ML. Effects of prior cold work and sensitization heat treatment on chloride stress corrosion cracking in type 304 stainless steels. Corrosion Science. 2001; 43(8):1519-1539. http://dx.doi. org/10.1016/S0010-938X(00)00165-7.

6. Hermas AA and Morad MS. A comparative study on the corrosion behaviour of 304 austenitic stainless steel in sulfamic and sulfuric acid solutions. Corrosion Science. 2008; 50(9):27102717. http://dx.doi.org/10.1016/j.corsci.2008.06.029.

7. Fauvet P, Balbaud F, Robin R, Tran Q-T, Mugnier A and Espinoux D. Corrosion mechanisms of austenitic stainless steels in nitric media used in reprocessing plants. Journal of Nuclear Materials. 2008; 375(1):52-64. http://dx.doi.org/10.1016/j. jnucmat.2007.10.017.

8. Albrimi YA, Addi AA, Douch J, Souto RM and Hamdani M. Inhibition of the pitting corrosion of 304 stainless steel in $0.5 \mathrm{M}$ hydrochloric acid solution by heptamolybdate ions. Corrosion Science. 2015; 90:522-528. http://dx.doi.org/10.1016/j. corsci.2014.10.023.

9. Tian W, Du N, Li S, Chen S and Wu Q. Metastable pitting corrosion of 304 stainless steel in $3.5 \% \mathrm{NaCl}$ solution. Corrosion Science. 2014; 85:372-379. http://dx.doi.org/10.1016/j. corsci.2014.04.033.

\section{5- Conclusions}

Considering the availability for the use of the Divosan solution and the calcium hypochlorite solution, and the corrosion resistance of steels in the two electrolytes, the aqueous solution of calcium hypochlorite is less aggressive to stainless steel. The austenitic AISI 304 steel showed the highest corrosion resistance in sanitizing electrolytes (calcium hypochlorite, and a solution of peracetic and acetic acid and hydrogen peroxide) used in the Clean-in-Place process of the food industry.

\section{Acknowledgements}

Authors would like to thank governmental agencies: National Council of Scientific and Technological Development (CNPq), Coordination of Improvement of Superior Level Staff(CAPES), and Foundation of Research Support in the State of Minas Gerais (FAPEMIG), and to APERAM South America to support this research.

10. Pardo A, Merino MC, Coy AE, Viejo F, Arrabal R and Matykina E. Effect of Mo and Mn additions on the corrosion behaviour of AISI 304 and 316 stainless steels in $\mathrm{H}_{2} \mathrm{SO}_{4}$. Corrosion Science. 2008; 50(3):780-794. http://dx.doi.org/10.1016/j. corsci.2007.11.004.

11. Kang DH and Lee HW. Study of the correlation between pitting corrosion and the component ratio of the dual phase in duplex stainless steel welds. Corrosion Science. 2013; 74:396-407. http://dx.doi.org/10.1016/j.corsci.2013.04.033.

12. Jorcin JB, Orazem ME, Pébère $\mathrm{N}$ and Tribollet B. CPE analysis by local electrochemical impedance spectroscopy. Electrochimica Acta. 2006; 51(8-9):1473-1479. http://dx.doi.org/10.1016/j. electacta.2005.02.128.

13. Orazem ME and Tribollet B. Electrochemical impedance spectroscopy. Hoboken: Wiley; 2008.

14. Belkaid S, Ladjouzi MA and Hamdani S. Effect of biofilm on naval steel corrosion in natural seawater. Journal of Solid State Electrochemistry. 2011; 15(3):525-537.

15. Zheng ZJ, Gao Y, Gui Y and Zhu M. Studying the fine microstructure of the passive film on nanocrystalline 304 stainless steel by EIs, XPS and AFM. Journal of Solid State Electrochemistry. 2014; 18(8):2201-2210.

16. Roberge PR. Handbook of corrosion engineering. New York: McGraw-Hill; 2000.

17. Zhao X, Zhang T, Zhou Y and Liu D. Preparation of peracetic acid from hydrogen peroxide Part I: Kinetics for peracetic acid synthesis and hydrolysis. Journal of Molecular Catalysis $A$ Chemical. 2007; 271(1):246-252. http://dx.doi.org/10.1016/j. molcata.2007.03.012.

18. Willenbruch RD, Clayton CR, Oversluizen M, Kim D and Lu Y. An XPS and electrochemical study of the influence of molybdenum and nitrogen on the passivity of austenitic stainless steel. Corrosion Science. 1990; 31:79-190.

19. McCafferty E. Introduction to corrosion science. New York: Springer; 2010.

20. Ilevbare GO and Burstein GT. The role of alloyed molybdenum in the inhibition of pitting corrosion in stainless steels. Corrosion Science. 2001; 43(3):485-513. http://dx.doi.org/10.1016/S0010938X(00)00086-X. 